\title{
AS RELAÇÕES DE PODER NO SEMIÁRIDO NORDESTINO
}

\author{
Alane Regina Rodrigues dos Santos ${ }^{1}$ \\ Carina Angélica dos Santos ${ }^{2}$ \\ Andréia Rodrigues dos Santos ${ }^{3}$
}

\section{RESUMO}

O semiárido brasileiro está compreendido em uma área de $982.566,3 \mathrm{~km}^{2}$ e abrange o norte do Estado de Minas Gerais, os sertões da Bahia, Sergipe, Alagoas, Pernambuco, Paraíba, Rio Grande do Norte, Ceará e Piauí, o que corresponde a 18,2 $\%$ do território nacional e abrange 1.133 municípios. O sertão é uma região caracterizada pela irregularidade de chuvas e pela semiaridez do seu clima que periodicamente assola a população. Devido essas particularidades, por muitos anos, o Nordeste enfrentou de forma extremamente hierarquizada, um processo civilizatório e colonizador no qual o deixou a mercê do clientelismo e dos grandes latifundiários. Diante desse contexto, o apadrinhamento e a forma patrimonialista marcaram o território nordestino, mais especificamente o semiárido, que por vários anos foi liderado pelos coronéis da região que concentravam todo o poder em suas mãos. Assim exposto, o presente artigo tem como objetivo geral discutir as relações de poder que ao longo dos anos vêm contribuindo com o quadro de dependência, extrema pobreza e aumento agudo da espoliação social da população do semiárido. São objetivos específicos, descrever como se deu a interferência do Estado em relação aos problemas relacionados com a problemática da seca, bem como identificar de que maneira vem ocorrendo a substituição patriarcal dos coronéis pelo assistencialismo governamental. Em princípio pretendeu-se descrever as características do semiárido nordestino e da seca que ocorre frequentemente na região. Em contrapartida, apresentam-se as relações de poder das classes dominantes que se beneficiaram, indevidamente, com os investimentos e subsídios oferecidos pelo governo. Em acréscimo, apresenta-se um breve recorte sobre os programas e políticas públicas voltadas para a convivência com o semiárido. É importante ressaltar, que os procedimentos metodológicos utilizados nesta pesquisa foram documental e bibliográfica em dissertações, teses, artigos, livros e periódicos relacionados com o tema. Nesta perspectiva, o presente estudo foi baseado pacificamente em autores conceituados, tais como: Weber (1999), Arendt (1985), Poulantzas (1985), Duarte (2001), Silva (2006) entre outros.

Palavras-Chave: Relações de Poder. Assistencialismo. Semiárido NE.

\footnotetext{
${ }^{1}$ Mestra e Doutoranda em Desenvolvimento em Meio Ambiente - UFS. E-mail: alane-rs@hotmail.com.

${ }^{2}$ Mestra e Doutoranda em Desenvolvimento em Meio Ambiente - UFS.

${ }^{3}$ Graduanda em Serviço Social da Universidade Federal de Sergipe.
} 


\section{ABSTRACT}

The Brazilian semiarid region is comprised in an area of 982,566.3 km2 and covers the northern state of Minas Gerais, the backlands of Bahia, Sergipe, Alagoas, Pernambuco, Paraíba, Rio Grande do Norte, Ceará and Piauí, which corresponds to $18,2 \%$ of the national territory and covers 1.133 municipalities. The hinterland is a region characterized by irregular rainfall and the semiaridity of its climate that periodically plagues the population. Because of these features, for many years, the Northeast faced in an extremely hierarchical way, a civilization and colonization process and has been left at the mercy of patronage and large landowners. In this context, sponsorship and the patrimonial form marked the northeastern territory, specifically the semi-arid region, which for several years was led by colonels of the region that concentrated all power in their hands. Thus exposed, this article has the general objective to discuss the relations of power that over the years have contributed to the condition of dependence, extreme poverty and acute increase in social dispossession of semiarid population. The specific objectives are to describe how was the interference of the state in relation to the problems associated with drought problems and identify how it has occurred patriarchal replacement Colonels by government welfare. In principle we aimed to describe the characteristics of the semiarid northeast and the drought that often occurs in the region. On the other hand, we presents the power relations of the ruling classes who have benefited unduly from investments and subsidies offered by the government. In addition, it presents a short cut on the programs and policies aimed at coexistence with the semiarid region. Importantly, the methodological procedures used in this study were documents and literature in dissertations, theses, articles, books and periodicals related to the subject. In this perspective, the present study was based on peacefully respected authors such as: Weber (1999), Arendt (1985), Poulantzas (1985), Duarte (2013), Silva (2006) among others.

Keywords: Power Relations. Welfarism. Semiarid NE. 


\section{Introdução}

Por muito tempo, o Nordeste brasileiro, em particular o semiárido, esteve em evidência como "região problema" do Brasil. O sertão nordestino tem sua história socioeconômica e política diretamente associada ao seu caráter de território onde se instalou uma atividade acessória à antiga economia açucareira da Zona da Mata. Neste lugar, não foi a mão de obra escrava que serviu de base ao sistema produtivo, mas sim a unidade familiar atrelada ao que veio a ser o latifúndio. Esse antigo modelo se formou a partir do sistema de sesmarias, e se valeu de formas pré-capitalistas de exploração, tais como, a parceria e a meação (CHACON; BURSZTYN, 2011).

Dessa forma, desde a época da colonização até os dias atuais o mandonismo está presente no Brasil. Por muitos anos, o Nordeste enfrentou de forma extremamente hierarquizada, um processo civilizatório e colonizador no qual o deixou a mercê do clientelismo e dos grandes latifundiários.

Diante desse contexto, o apadrinhamento e a forma patrimonialista marcaram o território nordestino, mais especificamente o semiárido, que por vários anos foi liderado pelos coronéis da região que concentrava todo o poder em suas mãos.

Por outro lado, o Estado capturado por interesses dos diferentes grupos que assumem o poder, foi incapaz de fortalecer o sertão como espaço diferenciado, com organização social e produtiva próprias. As políticas públicas não se preocupam em olhar este lugar e escutar com atenção seu povo, apenas repetem há décadas uma postura de falta de comprometimento, justificada na maioria das vezes por uma suposta inviabilidade econômica e produtiva da região (CHACON; BURSZTYN, 2011).

Assim exposto, o presente artigo tem como objetivo geral discutir as relações de poder que ao longo dos anos vêm contribuindo com o quadro de dependência, extrema pobreza e aumento agudo da espoliação social da população do semiárido. São objetivos específicos, descrever como se deu a interferência do Estado em relação aos problemas relacionados com a problemática da seca, bem como identificar de que maneira vem ocorrendo à substituição patriarcal dos coronéis pelo assistencialismo governamental. 
Em princípio pretendeu-se descrever as características do semiárido nordestino e da seca que ocorre frequentemente na região. Em contrapartida, apresentam-se as relações de poder das classes dominantes que se beneficiaram, indevidamente, com os investimentos e subsídios oferecidos pelo governo. Em acréscimo, apresenta-se um breve recorte sobre os programas e políticas públicas voltadas para a convivência com o semiárido.

\section{O semiárido e seus problemas socioambientais}

O semiárido brasileiro está compreendido em uma área de 982.563,3 $\mathrm{km}^{2}$ e abrange o norte do Estado de Minas Gerais, os sertões da Bahia, Sergipe, Alagoas, Pernambuco, Paraíba, Rio Grande do Norte, Ceará e Piauí. São três os critérios usados para definir as áreas semiáridas nordestinas:

- Precipitações pluviométricas médias anuais iguais ou inferiores a 800 $\mathrm{mm}$;

- Índice de aridez entre 0,5 e 0,21, calculado pelo balanço hídrico que relaciona as precipitações e a evaporação potencial, no período de 1961 a 1990;

- Risco de seca superior a 60\%, relativo ao período de 1970 a 1990 (BRASIL, 2005).

Com base nessas informações, a região semiárida caracteriza-se pela deficiência e/ou irregularidade de chuvas, onde a evaporação normalmente supera a precipitação, provocando a perda de grande parte da água superficial e a intermitência de quase toda a rede hidrográfica constituindo um severo problema para a captação e o armazenamento desse recurso essencial. Nessas áreas o fenômeno da seca assola a população periodicamente (REBOUÇAS, 2002). De acordo com Duarte "as secas podem ocorrer sob a forma de drástica diminuição ou de concentração espacial e/ou temporal da precipitação pluviométrica anual" (2001, p. 425). 
Seguindo o mesmo raciocínio, Andrade (1986) apresenta uma divisão dos tipos de seca presentes no sertão nordestino. Neste sentido, destaca que:

[...] há dois tipos de seca no Nordeste, a anual, que dura de sete a oito meses, correspondendo ao longo período de estio entre dois períodos chuvosos de três a quatro meses, e que não se constitui um grande problema, de vez que o sertanejo já está adaptado a ela e dispõe de reservatórios d'água que dão para atravessar este período. Ao lado desta existem as secas periódicas, de difícil previsão e que se efetivam quando em um período normalmente chuvoso - dezembro a março - não caem as chuvas esperadas, fazendo com que aquele período seco de sete a oito meses se estenda por dois e às vezes três a quatro anos (ANDRADE, 1986, p. 126).

Observa-se então, que o fenômeno da seca pode ter duas variantes, porém, um mesmo dilema: a primeira acontece anualmente no período chuvoso, desta a população esta inteiramente adaptada; a outra variante é caracterizada como uma seca mais longa e danosa, pois se alastra por mais tempo na região, provocando diversos problemas socioambientais.

A situação de desigualdade hierarquizada nas inter-relações sociais, promotora de pobreza e dependência dos sertanejos, nos períodos secos, se acirra ainda mais e vem, em muitos casos, a tomar a proporção de calamidade social. Nestes períodos, a maior parcela das atividades econômicas é prejudicada, levando à progressiva escassez de víveres e o sertanejo é forçado a submeter-se a uma dieta cada vez mais restritiva em sua alimentação, que pode chegar a inviabilizar a sobrevivência orgânica. Se no Nordeste Açucareiro tem-se uma região de fome endêmica, no Sertanejo, a fome surge em surtos epidêmicos. Relacionando-se diretamente com a criticidade das épocas de secas e contrastam com os períodos de relativa fartura de alimentos dos períodos chuvosos, que caracterizam a vida do sertanejo. Nos períodos de seca, a fome apresenta-se generalizada, uma fome que tanto é qualitativa, quanto é quantitativa, submetendo a população dessa região ao flagelo humano (CASTRO, 1984).

Atualmente, nesta época de mercado livre capitalista, sérias modificações têm ocorrido, favorecendo, dentre as várias consequências, o aprofundamento da exclusão dos menos favorecidos, que remete às desigualdades sociais e contradições impetradas pela soberania dos ditames do momento socioeconômico e político, 
caracterizado pelo capital globalizado. É a época da globalização econômica, processo excludente, que escolhe apenas algumas áreas específicas, orientando investimentos significativos para crescer e manter a competitividade econômica do mercado internacional, e ignorando grandes áreas, que ficam excluídas ou desprotegidas de uma participação representativa nos mercados e nos processos de produção de bens (CARVALHO, 2002). Porém, durante séculos:

Todos os problemas do Nordeste tinham sido reduzidos a um só grande problema: o das secas [...] considerado como fatalismo climático, contra o qual nada ou quase nada poderia fazer o homem. Daí o conformismo, a inércia, a ausência de quaisquer medidas tendentes a melhorar a situação das populações expostas ao flagelo. Só depois da seca de 1877 [...] é que o governo brasileiro tomou a iniciativa de realizar um plano, não de luta contra o flagelo da seca, mas de ajuda e de amparo aos flagelados da seca (CASTRO, 1967apud TORRES; SILVA; MARCOLINO, 2013, p. 5).

Com base nesse aspecto, percebe-se que a população do semiárido nordestino enfrenta secularmente graves problemas relacionados com a escassez de água, sendo que muitas ações de combate a esse impacto já foram planejadas, entretanto, essas ações não foram suficientes para suprir tamanho problema que se alastra todos os anos, principalmente no período de estiagem.

Diante do exposto, percebe-se que quando ocorre uma grande seca a produção agrícola se perde, a pecuária é debilitada ou até mesmo dizimada e as reservas superficiais de água se exaurem. Nessas condições, as camadas mais pobres da população rural ficam totalmente vulneráveis ao fenômeno climático e aos grandes latifundiários. Historicamente, a sobrevivência destes tem dependido das políticas oficiais de socorro, "apadrinhamento", ou recorrem à emigração para outras regiões ou para as áreas urbanas do próprio Nordeste (DUARTE, 2001).

\section{As relações de poder e o conformismo da população}

Por muitos anos o nordeste do Brasil, mais especificamente o semiárido, foi palco de muitas lutas sociais e políticas que marcaram de maneira complexa todo o seu território. As relações de poder 
concentradas nas mãos dos grandes latifundiários, dos coronéis e das representações políticas e religiosas, que foram os principais agentes responsáveis pelas decisões e práticas políticas, arcaicas e conservadoras, que por muitas décadas assolaram ainda mais os problemas de justiça social da população do semiárido.

Segundo Arendt (apud SOUZA, 1995):

[...] o poder jamais é propriedade do indivíduo; pertence ele a um grupo e existe apenas enquanto o grupo se mantiver unido. Quando se diz que alguém está 'no poder', estamos na realidade nos referindo ao fato de encontrar-se esta pessoa investida de poder, por um certo número de pessoas, para atuar em seu nome [...] (ARENDT apud SOUZA, 1995, p. 80).

De acordo com Poulantzas (apud SILVA, 2006, p. 56), o poder deve ser interpretado como a capacidade que tem uma classe social (ou determinadas classes sociais) de conquistar seus interesses específicos. Ainda de acordo com as contribuições desse autor, o poder de determinada classe significa, de início, seu lugar objetivo nas relações econômicas, políticas e ideológicas, isto é, envolve reações desiguais de dominação e subordinação. Por outra visão, o poder supõe a existência de uma bipolaridade na qual é possível identificar aqueles que exercem o poder e aqueles sobre quem é exercido, expressando, assim, uma relação de dominação.

É uma situação de fato, que a vontade manifesta (mandado) do dominador ou dos dominadores que influencia as ações de outras pessoas (do dominado ou dos dominados) e de fato as influências de tal modo que estas ações, num grau socialmente relevante, se realizam como se os dominados tivessem feito do próprio conteúdo do mando a máxima de suas ações (obediência) (WEBER apud SILVA, 2006, p. 56).

Desta forma, pode-se identificar que o exercício do poder se faz, não apenas pelas forças econômicas, mas também por questões de ordem política e cultural, que se expressam pelas estratégias e práticas de dominação. Sob o aspecto político a questão é mais crucial e sempre foi quanto à questão de: quem governa quem? Poder, força, autoridade e violência nada mais são do que palavras a indicar os meios pelos quais o homem governa o homem; são eles considerados sinônimos por terem a mesma função (ARENDT apud SOUZA, 1995). 
Com base nessas preposições, Weber afirma que a "dominação é um caso especial de poder [...] isto é, de possibilidades de impor ao comportamento de terceiros a vontade própria" (apud SILVA, 2006, p. 56). Neste sentido, pode-se observar que todas as áreas sociais, econômicas, políticas e culturais são influenciadas por muitos complexos de dominação e consequentemente por relações de poder.

Baseando-se no supracitado, o que torna as pessoas ainda dependentes dessas relações de poder na região nordeste do Brasil, é o fato de que além de conviver com a falta regular de chuva, a população enfrenta paulatinamente a estagnação econômica e os baixos índices sociais. Pois, o "conformismo da população juntamente com a exclusão social [ocorre] em função de processos econômicos, políticos e culturais excludentes", sendo estes processos marginalizantes que "implicam em não ter um lugar social" (CARVALHO, 2002, p. 10).

Diante dessa irônica realidade, ser um excluído, nesta situação, não significa estar por fora do capitalismo. Há uma inclusão de submissão via consumo, via ciclos periféricos de atividades, por exemplo: trabalho informal, e pelas formas de vida de excluídos, que se caracterizam por meios precários de trabalho, esporádicos e/ou itinerantes (CARVALHO, 2002).

\section{Coronelismo x Clientelismo}

Quando se analisa a situação socioeconômica brasileira, diante das diferenças regionais, que se inter-relacionam e constituem esta estrutura de desigualdade e de subdesenvolvimento nacional, vê-sena região Nordeste a manifestação dessa situação de forma aguda, como: os piores índices de disparidade social, de desorganização do mercado de trabalho formal, índices maiores de miséria, elevados patamares de analfabetismo, escolaridade insuficiente e, enfim, exclusão social na absoluta maioria dos municípios (AMORIM; POCHMANN apud NEPOMUCENO; PINHEIRO, 2010).

Por sua vez, o Nordeste Sertanejo é caracterizado pela área mais distante do litoral, na qual se propiciou a atividade de criação de animais de pastoreio e carga. Nesse também se desenvolveu naturalmente a agricultura de subsistência e é maculado pelo fenômeno 
da seca, que acomete a vida dos nordestinos e corresponde a uma dimensão de maior impacto do que simplesmente a climática ou natural, tornando-se um fenômeno social, político e econômico, de consequências calamitosas para a população. Ademais, desenvolveu-se uma sociedade ligada aos grandes proprietários de terras, onde as relações sociais são perpassadas pelo poder reservado a estes "coronéis", e pela resignação e dependência de sua mão de obra frente àqueles. Os grandes latifúndios e os engenhos de açúcar tinham proximidade econômica, independente da distância física, pois a pecuária das grandes propriedades almejava o mercado interno como principal objetivo da produção (NEPOMUCENO; PINHEIRO, 2010).

No Nordeste Brasileiro, o engenho de açúcar, constituiu-se como centro socioeconômico básico, que norteou o processo civilizatório da colonização. Nesse, o dono era a autoridade absoluta, mediante um poder total e brutal. O senhor-de-engenho detinha a posse da casa, da terra, dos equipamentos, da matéria-prima e dos escravos, que além de trabalhadores subjugados eram objetos com valor de troca. Exercendo desta maneira, uma autocracia nuclear, podendo explorar qualquer coisa ou pessoa com absoluto arbítrio (RIBEIRO, 2000). Assim,

\footnotetext{
A estrutura agrária constitui uma das fontes básicas do atraso no Nordeste Semiárido, em virtude de sua forte concentração nas mãos de um pequeno grupo de proprietários de terra, impedindo sua utilização econômica e social por quem queira e necessite fazer uso produtivo - os inúmeros pequenos produtores rurais (CARVALHO, 1988, p. 140).
}

Dessa forma, a preponderância e a expressividade social dos "coronéis" tornaram-se tão notórias nessa sub-região que, muitas vezes, era também percebida em todos os confins do país. Tal poder teve seu fortalecimento no cunho central e dominante dos latifúndios no semiárido, o que tornou os coronéis verdadeiros "senhores" da vida na região. Com o avanço da industrialização no Brasil, ocorrida principalmente durante as últimas décadas do século $\mathrm{XX}$, houve um enfraquecimento progressivo da influência dos grandes proprietários do sertão. Porém, se antes seu poder era mais amplo e arbitrário, nos dias atuais, sua influência parece ainda ser bastante significativa na tomada de decisões políticas e na ordenação socioeconômica da região. Se, em nível nacional, os poderosos coronéis perderam o poder econômico e político, no regional ainda impõem-se uma ordem oligárquica continuada, desde a época do Brasil colonial, a conduzir, 
de acordo com seus interesses, as relações junto ao poder público no Nordeste (NEPOMUCENO; PINHEIRO, 2010).

\section{O papel do Estado no desenvolvimento do semiárido}

A população do semiárido nordestino enfrenta secularmente graves problemas relacionados com a escassez de água e concentração de poder nas mãos de poucos, sendo que muitas ações de combate a esses efeitos foram realizadas. No entanto, essas ações não foram suficientes para suprir tamanho problema que se alastra todos os anos, principalmente no período de estiagem.

Neste sentido, pode-se observar que o semiárido possui uma trajetória marcada por diversos conflitos e eventos relacionados com a escassez de água. Esses conflitos, além de provocar inúmeros problemas de justiça ambiental, causam impactos desiguais nos grupos sociais que há décadas vem sendo castigados com a falta de recursos.

Nesta ótica, é possível identificar que os impactos ocorrem em um espaço social heterogêneo e natural, provocados pelas irregularidades de chuvas e pela falta de políticas públicas voltadas para o desenvolvimento do semiárido. Além do quadro de escassez, são diversos os problemas ocasionados pela seca, que exigem, cada vez mais, soluções específicas.

Como ver-se-á adiante, para atenuar os efeitos socioambientais provocados pelo déficit hídrico no semiárido nordestino, o governo federal desenvolveu, especificamente a partir do século $\mathrm{XX}$, políticas públicas para combater os efeitos provocados pelos frequentes períodos de estiagem.

Em 1909 o Departamento Nacional de Obras Contra as Secas (DNOCS), conhecido também sob o nome de Inspetoria de Obras Contra as Secas (IOCS) que está inteiramente vinculada ao Ministério da Integração Nacional, sendo considerado um dos principais órgãos responsáveis em combater os problemas no semiárido nordestino.

Além da criação do DNOCS, nessa mesma década foi criada a Superintendência do Desenvolvimento do Nordeste (SUDENE), órgão 
paralisado em 2001 e retomado no ano de 2007, com a função de administrar e caracterizar um fundo de recursos que fosse capaz de financiar as atividades agropecuárias no Nordeste e, consequentemente, aumentar o desenvolvimento nessa região.

Outra ação governamental de combate aos efeitos socioambientais provocados pela seca foi a criação de uma legislação específica para a região, que passou a ser caracterizada como Polígono das secas.

O denominado Polígono das Secas foi criado pela Lei $\mathrm{n}^{\circ} 175$ de janeiro de 1936, como área a ser objeto das políticas de combate às secas. O Polígono foi alvo de várias modificações. Tais que "[...] de 1936 a 1989, a superfície do Polígono foi ampliada e passou de 672.281,98 $\mathrm{km}^{2}$ para 1.085.187 km" (BRASIL, 2005, p. 9). Pois, neste ano por consequência da "Constituição Federal de 1988. Sua delimitação foi realizada de acordo com as disposições da Lei ${ }^{\circ}$ 7.827, de 27.09.1989, que instituiu o FNE” (BRASIL, 2005, p. 9), e designou a Região Semiárida do Fundo Constitucional de Financiamento do Nordeste.

No contexto atual, o Programa Um Milhão de Cisternas Rurais (P1MC), em parceria com o programa de Formação e Mobilização Social para a Convivência com o Semiárido da ASA tem ajudado as famílias rurais do Nordeste Brasileiro a conviver com os impactos socioambientais provocados pela seca, no entanto, a maioria da população ainda sofre com a constante espoliação social em que vivem periodicamente, principalmente no período de estiagem.

Nesta perspectiva, percebe-se que mesmo com a criação de programas, órgãos, leis e ações de combate à seca realizadas pelo Estado nas últimas décadas, muitos são os problemas que ainda assolam e prejudicam o desenvolvimento do semiárido brasileiro, ou seja, a falta de acesso à água pelas populações rurais difusas, a concentração de poder dos grandes latifundiários e a extrema pobreza que vive a população dessa região é, na atualidade, uma das principais preocupações da sociedade brasileira. 


\section{Considerações Finais}

O semiárido nordestino convive há séculos com as distintas relações de poder presentes em seu território, dentre os muitos aspectos apresentados neste trabalho, percebe-se que o mais expressivo em destaque é a exploração intensa da força de trabalho por parte dos latifundiários e os impactos provocados pela seca. Dessa forma, as principais causas da seca existentes no Nordeste são originadas por fatores naturais atribuídos ao baixo índice pluviométrico anual, baixa umidade, clima semiárido, solo rachado, bem como, um quadro agudo e constante de pobreza.

Nesta região, constate-se que além de conviver com a falta regular de chuva, a população enfrenta paulatinamente a estagnação econômica, baixos índices sociais e concentração de poder nas mãos de poucos. Neste sentido, o que torna a escassez de água um fator excludente e perverso na região é a extrema zona de exploração em que vive a maior parte da população.

Dessa forma, as famílias que residem no sertão nordestino carecem cada vez mais de políticas públicas voltadas para as suas particularidades, isto é, que sejam capazes de promover o desenvolvimento sustentável e uma postura conservadora em relação às reais dificuldades socioeconômica da população e não somente aos interesses particulares que por séculos vêm dominando o semiárido nordestino brasileiro.

\section{Referências}

AMORIM, Ricardo; POCHMANN, Marcio. Atlas da Exclusão Social no Brasil. São Paulo: Cortez, 2003.

ANDRADE, M. C.A intervenção do Estado e a seca no Nordeste do Brasil. Revista de Economia Política, São Paulo, v. 6, n. 4, p. 125 130, 1986. Disponível em: <http://www.rep.org.br/PDF/24-9.PD>. Acesso em: 28 nov. 2013.

BRASIL. Ministério do Meio Ambiente. Secretaria de Recursos Hídricos. Programa de ação nacional de combate à desertificação 
em mitigação dos efeitos da seca PAN-Brasil. Brasília/DF: MMA, 2005.

Disponível

em:

<http://www.mma.gov.br/estruturas/sedr_desertif/_arquivos/pan_brasil _portugues.pdf $>$. Acesso em: 28 nov. 2013.

BRASIL. Agência Nacional de Águas. Conjuntura dos recursos hídricos no Brasil. Brasília/DF: ANA, 2005.

CARVALHO, O. A Economia Política do Nordeste: seca, irrigação e desenvolvimento. Rio de Janeiro: Campus,1988.

CARvalho, A. M. P. As Políticas Públicas no Brasil Contemporâneo: relação Estado-Sociedade. Natal/RN: UFRN, 2002.

CASTRO, Josué de. Sete palmos de terra e um caixão: ensaio sobre o Nordeste, área explosiva. 2. ed. São Paulo: Brasiliense, 1967.

CASTRO, J. Geografia da Fome; o dilema brasileiro: pão ou aço. 10. ed. Rio de Janeiro: Antares, 1984.

CHACON, S. S. BURSZTYN, M. Ligações perigosas: proteção social e clientelismo no Semiárido Nordestino. Estudos Sociedade e Agricultura, Rio de Janeiro, v. 19, n. 1, p. 30-61, 2011. Disponível em:http://www.plataformademocratica.org/Publicacoes/21055_Cached .pdf>. Acesso em: 28 nov. 2013.

DUARTE, R. Seca. Pobreza e políticas públicas no nordeste do Brasil. In: ZICCARDI, A. (comp.). Pobreza,desigualdad social y cidadania: Los límites de las políticas sociales en América Latina.Buenos Aires: CLACSO, 2001. p. 425-440. Disponível em: <http://biblioteca.clacso.edu.ar/clacso/gt/20101030020924/16duarte.pd f >. Acesso em: 15nov. 2013.

NEPOMUCENO, L. B.; PINHEIRO, A. A. A. Elementos psicossociais para compreender o Nordeste. Revista de Psicologia, Fortaleza, v. 1, n. 1, p. 85-104, jan.-jun. 2010. Disponível em: $<$ http://www.revistapsicologia.ufc.br/images/pdf/ano1edicao1/ano1 edicao1007.pdf >. Acesso em: 10 nov. 2013. 
REBOUÇAS, A. C. Água doce no mundo e no Brasil. In: REBOUÇAS, A. C.; BRAGA, B.; TUNDISI, J. G. Águas doces no Brasil: capital ecológico, uso e conservação. 2. ed. rev. e ampl. São Paulo: Escrituras, 2002. cap. 1. p. 1-37,

RIBEIRO, D. O Povo Brasileiro: a formação e o sentido do Brasil. 2. ed. São Paulo: Companhia das Letras, 2000.

POULANTZAS, Nico. O estado, o poder e o socialismo. Rio de Janeiro: GRAAL, 1985.

PONTES, E. T. M.; MACHADO, T. A. Desenvolvimento Sustentável e Convivência com o Semiárido caso do programa um milhão de cisternas rurais no nordeste brasileiro. In: ENCONTRO NACIONAL DE GEOGRAFIA AGRÁriA, 19, São Paulo. Anais... São Paulo: DG/FFLCH/USP, 2009. p. 1-25. Disponível em: <http://www.geografia.fflch.usp.br/inferior/laboratorios/agraria/Anais \%20XIXENGA/artigos/Pontes_ETM.pdf >. Acesso em: 20 nov. 2013.

SILVA, A. B. Relações de poder, fragmentação e gestão do território no semiárido nordestino: um olhar sobre o Cariri Paraibano. 2006. 318 f. Tese (Doutorado em Ciências Sociais) Universidade Federal do Rio Grande do Norte, Natal, 2006.

SOUZA, M. L. O território: sobre espaço e poder, autonomia e desenvolvimento. In: CASTRO, I. E.; GOMES, P. C. C.; CORREA, R. L. (orgs.). Geografia: conceitos e temas. Rio de Janeiro: Bertrand Brasil, 1995. p. 77-116.

TORRES, A. C. M.; SILVA, R. T.; MARCOLINO, M. R. T. Cooperativismo e convivência com a seca: o caso da COOPAPI no RN. Geo Temas, Pau dos Ferros/RN, v. 3, n. 1, p. 03-13, jan.-jun. 2013. Disponível em: <http://www2.uern.br/index.php/geotemas/article/viewFile/521/373>. Acesso em: 20nov. 2013.

WEBER, Max. Sociologia da dominação. In: Economia e sociedade: fundamentos da sociologia compreensiva. v. 2. Brasília, DF: UNB, 1999b. p. 187 - 193. 